\section{ScienceDirect}

Materials Today: Proceedings 6 (2019) 310-313 $\underset{\text { MROCEREDINGS }}{\text { Materiada: }}$

www.materialstoday.com/proceedings

\title{
UV-enhanced Ozone Sensing Response of Al-doped Zinc Oxide Nanocrystals at Room Temperature
}

\author{
S. Bernardini ${ }^{\mathrm{a}, *}$, T. Fiorido ${ }^{\mathrm{a}}$, K. Aguir ${ }^{\mathrm{a}}$, O. Margeat ${ }^{\mathrm{b}}$, J. Ackermann $^{\mathrm{b}}$, \\ C. Videlot-Ackermann ${ }^{\mathrm{b}}$ \\ ${ }^{a}$ Aix Marseille Univ, Univ Toulon, CNRS, IM2NP, Marseille, France \\ ${ }^{b}$ Aix Marseille Univ, CNRS, CINaM, Marseille, France
}

\begin{abstract}
In this work, we focus on ozone $\left(\mathrm{O}_{3}\right)$ detection at room temperature in the main objective to be well suited for most of flexible substrates. Aluminum doped zinc oxide (AZO) nanoparticles were deposited in thin films to be used as ozone gas sensors. It was demonstrated that the nanoparticles had good sensitivity to $\mathrm{O}_{3}$ at low temperature $\left(\leq 125^{\circ} \mathrm{C}\right)$ when the sensor was exposed to UV illumination. This study provides an easy and efficient way to obtain $\mathrm{O}_{3}$ gas sensors at temperature from $25^{\circ} \mathrm{C}$ up to $125^{\circ} \mathrm{C}$ by a simple and versatile solution-process. Electrical resistance measurements at $25^{\circ} \mathrm{C}$ under UV irradiation showed that AZO thin films were sensitive even at a low ozone concentration (35 ppb).
\end{abstract}

(C) 2018 Elsevier Ltd. All rights reserved.

Selection and/or Peer-review under responsibility of SURFOCAP 2017.

Keywords: Gaz Sensors; Ozone; Al-dpoed ZnO (AZO) nanoparticles; Thin films.

\section{Introduction}

In this work, we focus on ozone $\left(\mathrm{O}_{3}\right)$ detection at room temperature to be well suited for most of flexible substrates. $\mathrm{O}_{3}$ is naturally present in the atmosphere due to the interaction of sunlight with chemicals emitted into the environment [1]. At ground level ozone is harmful even at low concentrations and leads to health problems such as inflammation and congestion of the respiratory tract [2]. $\mathrm{O}_{3}$ detection can be acquired by monitoring the

* Corresponding author. Tel.: +33049128 89 71; fax: +33 0491288970 .

E-mail address: sandrine.bernardini@im2np.fr 
conductance changes in oxide semiconductor thin-films as Zinc Oxide ( $\mathrm{ZnO})$. For gas sensor devices, a large surface-area-to-volume ratio favors the adsorption of the gases on its surface [3]. We have shown previously that $\mathrm{ZnO}$ nanoparticles (NPs) can be used as sensitive layer to detect $\mathrm{O}_{3}$ at $200^{\circ} \mathrm{C}$ on flexible substrate [4]. When $\mathrm{ZnO}$ is doped with group III elements such as Aluminum, it is expected that the dopants act as singly charged donors and supply the excess carriers to conductance band, which will increase the conductivity [5]. Furthermore, illuminating sensitive layers with ultra-violet (UV) light improves sensing performances [6].

We propose herein $\mathrm{O}_{3}$ detection at temperature ranging from $25^{\circ} \mathrm{C}$ to $125^{\circ} \mathrm{C}$ by Aluminum doped zinc oxide (AZO) NPs deposited on rigid substrate to form porous thin films composed of tightly packed grains. Electrical resistance measurements at $25^{\circ} \mathrm{C}$ under UV irradiation showed that $\mathrm{AZO}$ thin films were sensitive even at low ozone concentrations (35 ppb).

\section{Experimental section}

\subsection{Materials and methods}

AZO NPs were prepared following procedures described previously [7,8]. In a typical experiment, AZO NPs were produced by adding zinc acetate, aluminum isopropylate and distilled water into a flask containing anhydrous ethanol. After heating at $80^{\circ} \mathrm{C}$, potassium hydroxide dispersed in ethanol was added dropwise to the flask, and heating was kept at $80^{\circ} \mathrm{C}$ during $16 \mathrm{~h}$. The as-synthesized AZO NPs were washed by centrifugation. By controlling the initial ratio of the aluminum to zinc precursor during synthesis while keeping constant all the other parameters, a precise control of $\mathrm{Al}$ doping content (atomic percentage, at.\%) can be obtained. In the present study, AZO NPs with 0.8 at.\% Al doping level have been synthesized. The solution-processable dispersions were prepared by transferring the synthesized AZO NPs from medium reaction to isopropanol at concentrations of $30 \mathrm{mg} \cdot \mathrm{mL}^{-1}$. Additionally, cluster-free dispersions of AZO NPs were obtained in isopropanol by using 0.2 vol.\% of ethanolamine (EA) as surfactant [7]. EA is a small organic molecule giving high dispersions without aggregate in alcohols and avoiding the need of bulky or long surfactants.

\subsection{Sensor assembly}

Our sensors consist of two interdigitated platinum electrodes, obtained by standard pulverization method on silicon dioxide in a resistor configuration (Fig. 1). Then, AZO NPs disperse in isopropanol, using 0.2 vol.\% of EA, were dropped on the electrodes in order to reach a sensitive film thickness around $200 \pm 10 \mathrm{~nm}$ as for our previous studies on $\mathrm{ZnO} \mathrm{NP}$ [4]. Finally, the deposited drop was dried at $150^{\circ} \mathrm{C}$ for $30 \mathrm{~min}$.

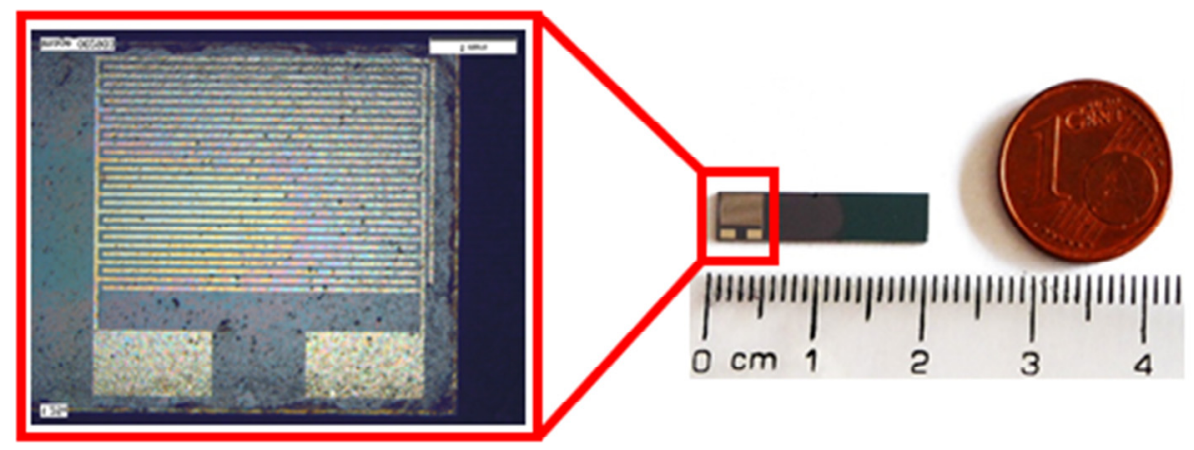

Fig. 1. Sensors fabricated on $\mathrm{Si} / \mathrm{SiO}_{2}$ based on $\mathrm{AZO}$ nanocrystals deposited by drop coating. 


\subsection{Gas sensing measurements}

The gas sensing properties of AZO films were investigated in a sealed stainless test cell to control the substrate temperature and $\mathrm{O}_{3}$ concentrations. Dry air was used as gas vector at $500 \mathrm{sccm}$. The sensor was exposed to dry air (i.e. $0 \%$ relative humidity) with different concentrations of $\mathrm{O}_{3}(35,65,125,165 \mathrm{ppb})$ during $30 \mathrm{~s}$ and exposed to a clean dry airflow for recovery. $\mathrm{O}_{3}$ gas was formed from oxidizing oxygen molecules of dry air by a calibrated penray UV lamp (UVP, model). The dry air, containing $\mathrm{O}_{3}$, was blown directly onto the sample placed on a heated holder. The applied dc voltage was $0.1 \mathrm{~V}$. The electrical resistance was measured using a Keithley (model 2450) source-meter connected to a computer. The detection response is defined as the normalized electric resistance response, by $S=R_{O_{3}} / R_{\text {dry air }}$, where $\mathrm{R}_{\mathrm{O} 3}$ and $\mathrm{R}_{\text {dry air }}$ are the electric resistances of the sensor exposed to $\mathrm{O}_{3}$ gas and to dry air, respectively. Gas sensing measurements under UV-light irradiation were performed using a UV-LED (UV5TZ-390-30, peak wavelength of $390 \mathrm{~nm}$ ) kept at $10 \mathrm{~mm}$ from the sensing material. Initially, the samples were irradiated for $60 \mathrm{~min}$ with a UV-LED to stabilize the electrical resistance.

\section{Results and discussion}

\subsection{Thin film Characterization}

Fig. 2 shows a typical Transmission Electron Microscopy (TEM) image of the AZO NPs with homogeneous sizes (diameters about $10 \mathrm{~nm}$ ) and shape dispersions. Previous analyses have shown that the AZO nanocrystals are monocrystalline with a classical wurtzite structure [7].

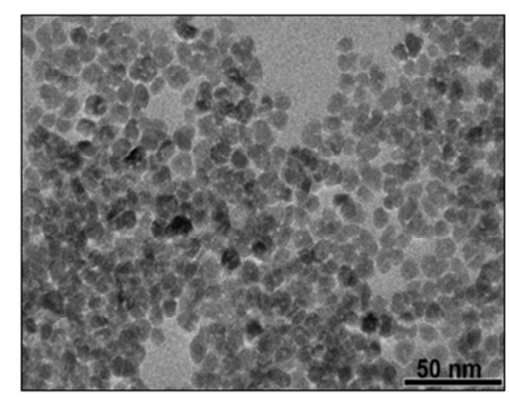

Fig. 2. TEM image of AZO nanocrystals drop-casted on a TEM grid.

By drop casting of AZO NPs-based dispersion, thin films with tightly packed grains are obtained. The freespaces between NPs offer a high surface-area-to-volume-ratio to the thin film where gas molecules can diffuse in the volume structure.

\subsection{AZO Sensor response}

The sample studied here was initially exposed to $\mathrm{O}_{3}$ at room temperature (around $25^{\circ} \mathrm{C}$ ) without any illumination. As can be seen in Fig. 3a, a slight $\mathrm{O}_{3}$ response was observed without recovery time. When the sample was exposed to $\mathrm{O}_{3}$ at $25^{\circ} \mathrm{C}$ under $\mathrm{UV}$ illumination, Fig. $3 \mathrm{~b}$, the sensitivity to $\mathrm{O}_{3}$ gas was enhanced over that without UV light with long recovery time. It presented total reversibility and had good stability of the base line. Figure $3 \mathrm{c}$ presents the comparison of sensor responses at room temperature in dark and under UV light. In ozone gas detection, the $\mathrm{O}_{3}$ gas molecules adsorb on the AZO surface, implying the formation of an electron-depletion layer due to adsorption of ions, which increases the potential barrier and consequently diminishes AZO conductivity. 

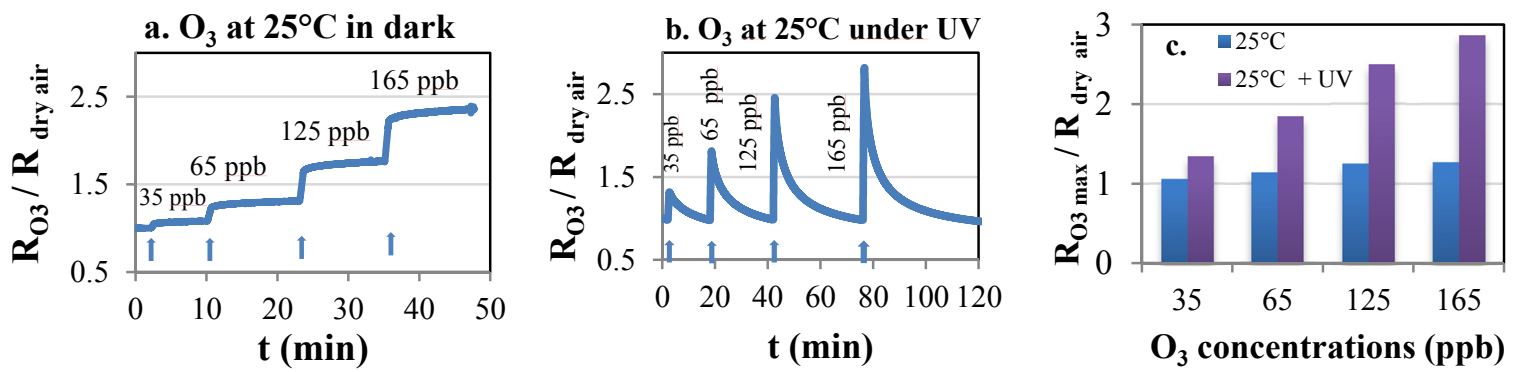

Fig. 3. Sensor responses as function of $\mathrm{O}_{3}$ concentrations at $25^{\circ} \mathrm{C}$ (a) in dark, (b) under UV and (c) comparison of both.

To decrease the recovery time under UV light irradiation, temperature is required. Fig. 4 presents the best response in terms of amplitude and recovery time acquired at $125^{\circ} \mathrm{C}$ under UV irradiation. The results obtained show fast responses at low level ozone concentration and good reversibility.

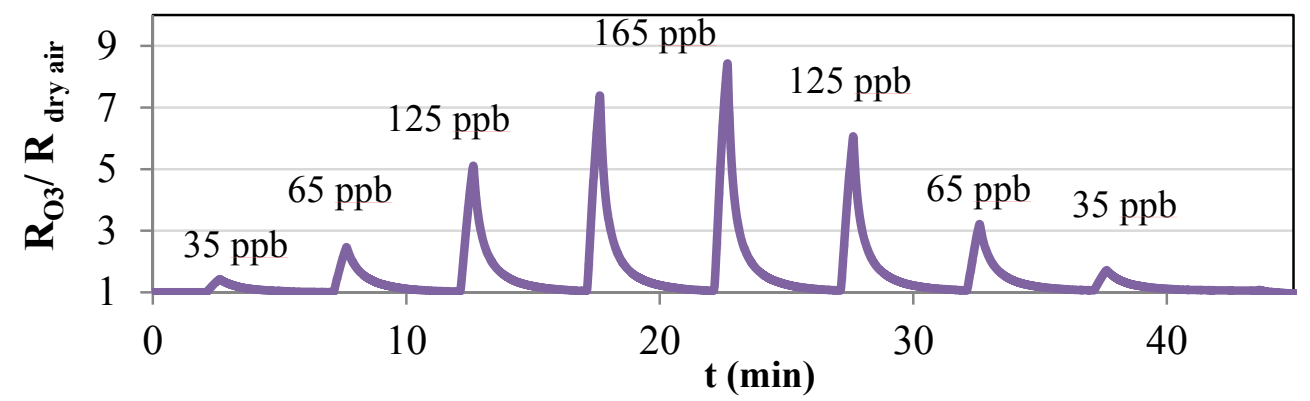

Fig. 4. Ozone exposure during 30s increasing from 35 to $165 \mathrm{ppb}$ and decreasing from 165 to $35 \mathrm{ppb}$ at $125^{\circ} \mathrm{C}$ under $\mathrm{UV}$.

\section{Conclusion}

This work reported a low-temperature way to detect $\mathrm{O}_{3}$ molecules by thin-film based sensors. Synthesized Aluminum doped $\mathrm{ZnO}$ nanoparticles with a controlled doping level ( 0.8 at. \% $\mathrm{Al})$ have been dropped casted to form a gas sensing layer. Gas sensing measurements showed the great potential of AZO nanoparticles, which display a fast response, short recovery time, at optimal temperature of $125^{\circ} \mathrm{C}$ under UV-light irradiation. This versatile methodology provides an alternative way to manufacture gas sensor devices, operating at low temperatures, which is compatible with flexible substrates. Electrical resistance measurements at $25^{\circ} \mathrm{C}$ under $\mathrm{UV}$ irradiation have shown that AZO thin films were sensitive even at low ozone concentrations.

\section{Acknowledgements}

The authors would like to express many thanks to A. Combes for his technical support in this work.

\section{References}

[1] S. Wakamatsu, T. Ohara, and I. Uno, Atmos. Environ vol. 30 (1995) pp. 715-721.

[2] Air Quality Guideline for Europe, EURO, World Health Organization, Regional, Copenhagen, European Series (1998).

[3] G. J. Cadena, J. Riu and F. X. Rius, Analyst, 132, (2007) pp. 1083-1099.

[4] M. Acuautla, S. Bernardini, and M. Bendahan, Key Engineering Materials 605 (2014) pp. 163-166.

[5] D.Y. Kim, J.Y. Son. Solid-State Lett. 12 (2009) pp. J109-J111.

[6] L. F. da Silva, J.-C. M'Pekob, A. C. Catto, et al. Sensors and Actuators B Chemical (2016) pp. 240:573-579.

[7] M. Gaceur, S. Ben Dkhil, D. Duché, et al. Adv. Funct. Mat. 26 (2016) pp. 243-253.

[8] A.K. Diallo, M. Gaceur, S. Fall, et al. Materials Science and Engineering: B, 214 (2016) pp.11-18. 